\title{
Microcephalic osteodysplastic primordial dwarfism type I/III in sibs*
}

\author{
Peter Meinecke, Eberhard Passarge
}

\begin{abstract}
The clinical and radiological findings in a pair of sibs with microcephalic osteodysplastic primordial dwarfism (MOPD) are described, a boy who survived for $5 \frac{1}{2}$ years and his more severely affected younger sister, who died at the age of 6 months. Neuropathological studies in this girl showed marked micrencephaly with severely hypoplastic, poorly gyrated frontal lobes and absent corpus callosum. Our observation supports the hypothesis that types I and III MOPD probably constitute a spectrum of one and the same entity and published data together with this report are consistent with autosomal recessive inheritance. The pathogenesis of this condition is as yet unknown, but its characteristics indicate a basic defect affecting cell proliferation and tissue differentiation.
\end{abstract}

In 1982 Majewski and Goecke ${ }^{1}$ re-evaluated microcephalic primordial dwarfism (including the ill defined 'Seckel syndrome') and consequently delineated a group of disorders which they term 'osteodysplastic primordial dwarfism types I, II, and III'. While type II is apparently a distinct disorder, shown by several examples, ${ }^{2-5}$ evidence is growing that types I and III are one and the same disorder, ${ }^{,-8}$ (Majewski, personal communication). Here we present a pair of sibs with this condition. This observation supports the hypothesis that types I and III microcephalic osteodysplastic primordial dwarfism

\footnotetext{
Abteilung Medizinische Genetik, Altonaer Kinderkrankenhaus, Bleickenallee 38, D-2000 Hamburg 50, Germany.

Peter Meinecke

Institut für Humangenetik, Universitätsklinikum Essen, Germany.

Eberhard Passarge

Correspondence to Dr Meinecke.
}

Received for publication 26 November 1990

Revised version accepted for publication 26 March 1991.

*This article is dedicated to Professor Jürgen Spranger on the occasion of his 60 th birthday.
(MOPD) are one entity and makes autosomal recessive inheritance likely.

\section{Case reports}

The proband (case 1) was referred to us in 1968 at the age of 16 months for genetic diagnostic evaluation because of severe developmental retardation with dwarfism and microcephaly. In 1974, we saw the younger sister (case 2) who was then 1 month old. At that time we recognised the striking similarity between our two patients and a probably autosomal recessive condition described by Taybi and Linder,' which they had termed 'cephalo-skeletal dysplasia'.

Case 1 was the first child of young, healthy, and non-consanguineous parents. Their second pregnancy had resulted in a normal girl. Case 2 was the product of the third pregnancy.

CASE 1

This male infant was born spontaneously after an uneventful pregnancy at 38 weeks of gestation. Birth length was $40 \mathrm{~cm}(-5.2 \mathrm{SD})$, weight $1650 \mathrm{~g}(-4 \mathrm{SD}$ for age), and head circumference (OFC) was $27 \mathrm{~cm}$ (-6.1 SD). Apgar score was 10. Apart from microcephaly and dwarfism, hypotrichosis, large eyes, deep set and small ears, and tapering of fingers were noted. Initially the boy sucked poorly and he was tube fed for five weeks. Growth and weight gain were poor and psychomotor development was severely retarded. A first tooth was noted at 12 months of age.

When we saw the boy at 16 months (fig 1), his length was $65 \mathrm{~cm}$ ( $-6 \mathrm{SD}$ ), weight $8500 \mathrm{~g}$ (3rd centile for age), and OFC $36 \mathrm{~cm}(-8.4 \mathrm{SD})$. His strikingly small skull with closed fontanelles had a trigonobrachycephalic shape, scalp hair was sparse, his eyes were slightly protruding, and the ears were low set, small, and poorly differentiated. His arms and legs appeared to be short, with short hands and feet which showed dorsal lymphoedema and short, tapering fingers and toes. The penis was small and there was cryptorchidism bilaterally. Apart from generalised hypotrichosis, the dry and hyperkeratotic skin was slightly scaling. Psychomotor development was severely retarded. The boy was able to 


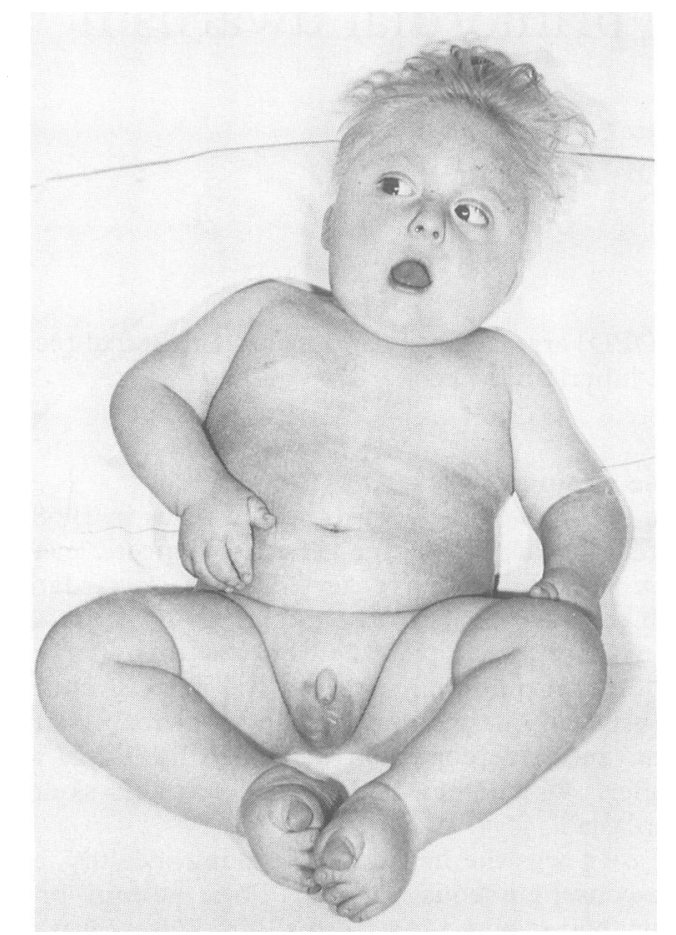

Figure 1 Case 1 aged 16 months. Note microcephaly, sparse hair, dorsal lymphoedema of hands and feet, tapering fingers, and hypoplastic genitalia.

grasp toys but could not sit. He showed some social contact with his parents.

TORCH titres were negative. Urinary amino acid chromatography and mucopolysaccharides were normal. Chromosomes (standard Giemsa stained) were normal. The boy's EEG was strikingly abnormal with generalised dysrhythmia and signs of convulsive potential.

\section{Radiological findings}

At the age of 3 weeks, the strikingly small skull (fig 2) showed a steep, sclerotic base, particularly small and sloping frontal bones, a well ossified occipital bone, and large orbits. The clavicles were relatively long and there were only 11 pairs of ribs. The spine showed mild platyspondyly. The iliac wings were rounded, and there were nearly horizontal, irregular acetabular roofs (fig 3). Both femora showed mild bowing of their shafts and there was no ossification of the epiphyses in the knee region. Calcaneus and talus were present. Joint spaces were strikingly narrow.

The hands (fig 4) and feet were small, the first metacarpals were slightly short, and the proximal

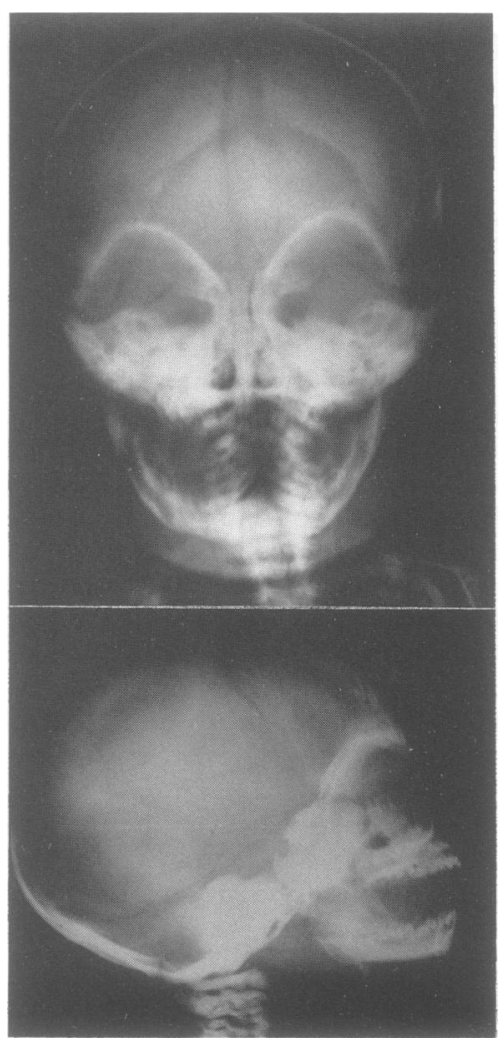

Figure 2 Case 1 aged 3 weeks. Note small skull with particularly small and sloping frontal bones.

phalanges of the big toes were particularly short and rounded.

\section{Clinical course}

There are only sparse data for the following years because the parents declined follow up visits. As far as we know, the boy remained dwarfed and microcephalic with severely retarded psychomotor development. At $5 \frac{1}{2}$ years, the patient died at home from an acute aphthous stomatitis complicated by purulent tonsillitis with high fever and vomiting. Necropsy was not performed.

\section{CASE 2}

This female infant (fig 5) was born at term after an uneventful pregnancy. Her length was $36 \mathrm{~cm}$ (-9 SD), weight $1400 \mathrm{~g}(-5.5 \mathrm{SD}$ for age), and OFC $26 \mathrm{~cm}(-7.5 \mathrm{SD})$. Apgar score was 10. Craniofacial anomalies included a microcephalic skull with sloping forehead, prominent occiput, and a very 


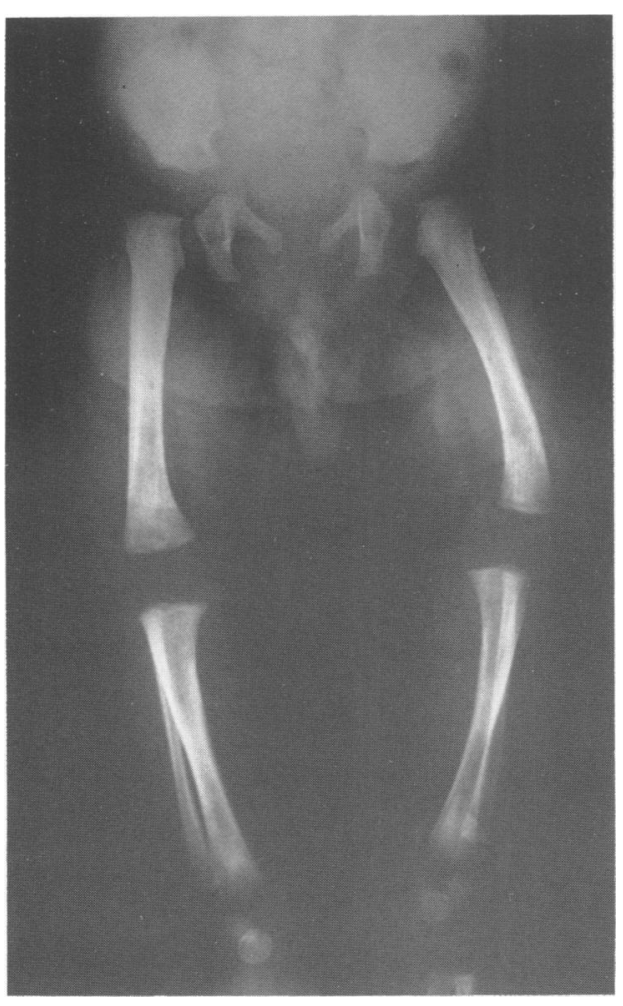

Figure 3 Case 1 aged 3 weeks. Note nearly horizontal and irregular acetabular roofs, narrow joint spaces, and lack of epiphyseal ossification of the femora.

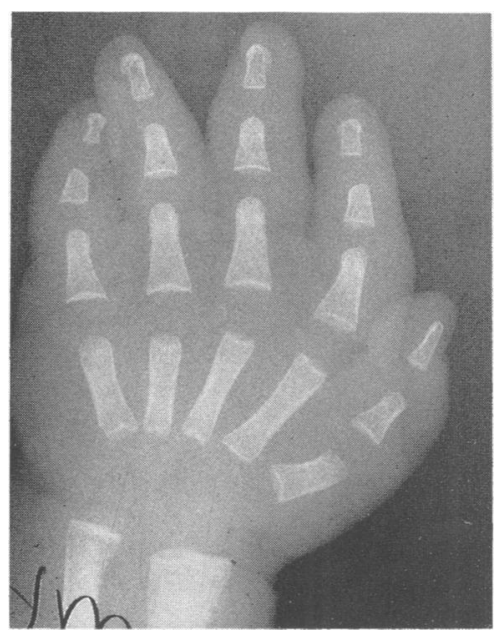

Figure 4 Hand of case 1 aged 3 weeks. small anterior fontanelle; large, slightly protruding eyes with upward slanting palpebral fissures; broad, flat nasal bridge and broad nasal tip with prominent columella; and short, poorly structured philtrum and moderate micrognathia. The ears were low set, small, and poorly modelled. The neck was short. External female genitalia were normal. The limbs appeared to be short, in particular her hands with proximally placed thumbs and tapering fingers. Rockerbottom feet showed dorsal lymphoedema. She had generalised hypotrichosis and a dry, hyperkeratotic, and scaling skin. Dermatoglyphics showed bilateral single palmar crease, palmar axial triradius in the $t^{\prime}$ position, and ulnar loops on all fingertips.

Laboratory studies including urinary amino acids and mucopolysaccharides excretion gave normal results. $\mathrm{G}$ banded chromosomes were normal.

\section{Radiological findings}

At birth, she had a strikingly small skull (fig 6) with a steep and sclerotic cranial base, small and sloping frontal bone, and a well ossified occipital bone with a protuberance (bathrocephaly).

A so-called 'babygram' (fig 7) showed long clavicles, poor ossification of the sternum, and only 11 pairs of ribs which were dorsally narrow. The spine was abnormal with moderate platyspondyly and coronal clefts of lumbar vertebral bodies (fig 8 ). The iliac wings were rounded with horizontal, irregular acetabular roofs. The long tubular bones of her arms and legs were short and poorly modelled. In addition, the cortices of both humeri were unusually thick. Bilateral malposition of the proximal radius suggested dislocation of the radial heads. Both hands showed ulnar deviation and there were rockerbottom feet bilaterally. The first metacarpals were slightly short and the proximal phalanges of the big toes were particularly short and rounded. While the talus and the calcaneus showed immature ossification, there was otherwise a total lack of epiphyseal ossification.

Re-examination at 5 months showed that the skull was still strikingly small, the long tubular bones remained undermodelled, and bone age was markedly delayed.

\section{Clinical course}

Feeding was uncomplicated but weight gain was slow. During the neonatal period a few seizures were noted which ceased after treatment with phenobarbital. At the age of 6 months, length was $45 \mathrm{~cm}$ (-8 SD), weight $3815 \mathrm{~g}$ (3rd centile for age), and OFC was $32 \mathrm{~cm}(-7 \mathrm{SD})$. The girl was able to follow objects with her eyes, but otherwise psychomotor development was severely retarded. At 6 


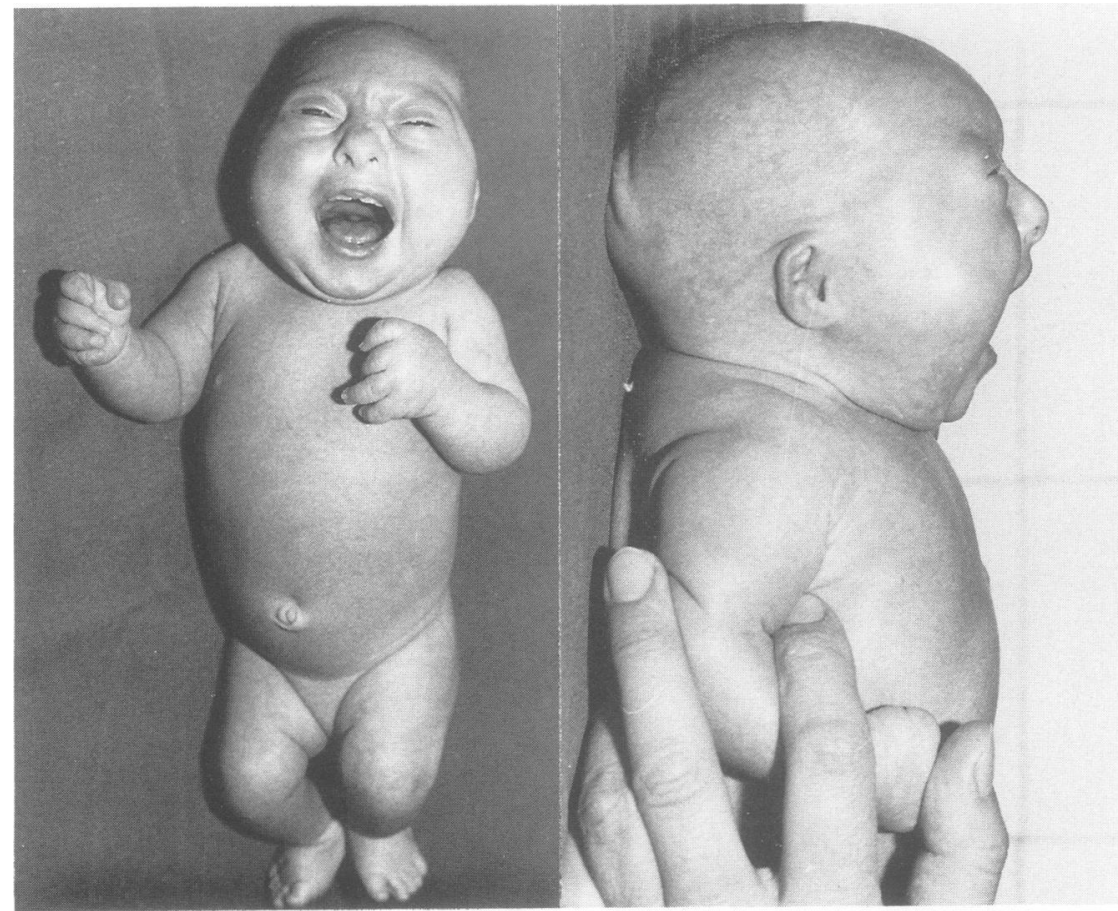

Figure 5 Case 2 at birth. Note microcephaly with sloping forehead and prominent occiput, low set and dysmorphic ears, short limbs, and hypotrichosis.

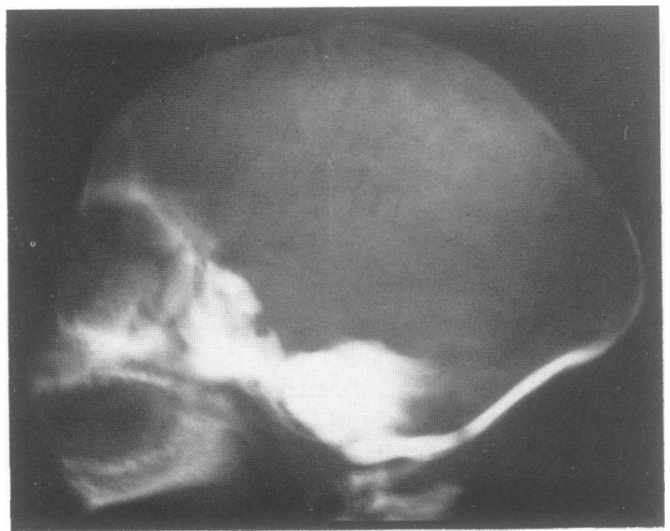

Figure 6 Case 2 at birth. Note small neurocranium and bathrocephaly.

months, she died suddenly at home from unexplained causes.

\section{Necropsy findings}

Necropsy showed no internal malformations apart from brain abnormalities. Neuropathological studies

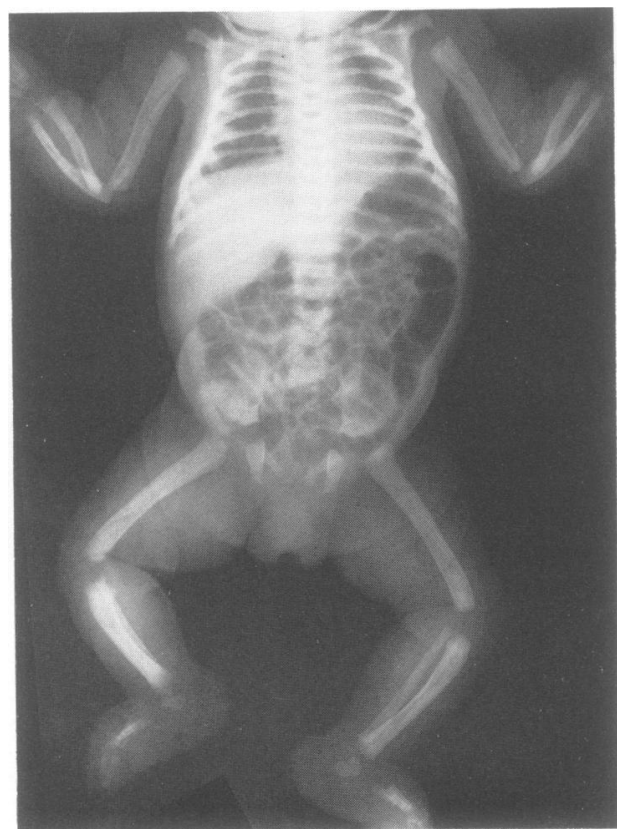

Figure 7 Case 2 at birth. Note 11 pairs of ribs, rounded iliac wings with horizontal, irregular acetabular roofs, and short, poorly modelled tubular bones of arms and legs. 


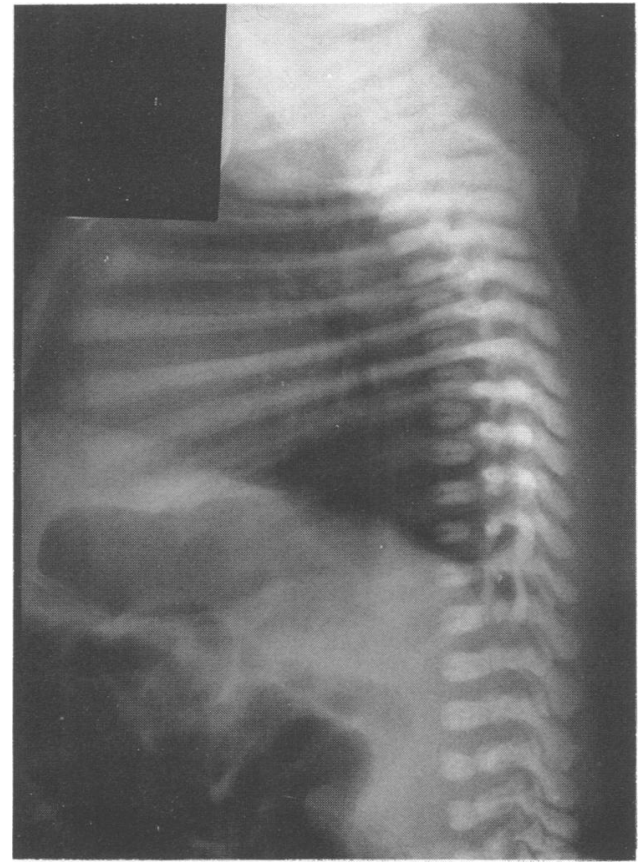

Figure 8 Case 2 at birth. Note moderate platyspondyly and coronal clefts of lumbar vertebral bodies.

(courtesy of Dr H Klein, Bremen) showed marked micrencephaly (brain weight $180 \mathrm{~g}$ ) with poorly gyrated telencephalon and particularly hypoplastic, nearly lissencephalic frontal lobes. The corpus callosum was absent (fig 9). Histologically, there were signs of severely arrested differentiation of the cerebral cortex and extremely reduced mass development of the white matter, whereas the brainstem and spinal cord showed normal architecture.

\section{Discussion}

Features common to this pair of sibs are primordial dwarfism, severe microcephaly, and a variety of external characteristics, such as large and protruding eyes, deep set, small, and poorly differentiated ears, micrognathia, short neck, short limbs, dorsal lymphoedema of the hands and feet, tapering fingers, and dry, scaling skin with strikingly sparse hair. In addition, psychomotor development is severely retarded.

Radiologically, both patients show a markedly small neurocranium, relatively long clavicles, 11 pairs of ribs only, rounded iliac wings with horizontal acetabular roofs, short and poorly modelled tubular bones, unusually narrow joint spaces, and markedly retarded epiphyseal maturation. Apart from severe microcephaly, neuropathological findings include strikingly arrested brain maturation, expressed by very hypoplastic frontal lobes, poor gyration of the cortex, absent corpus callosum, and histologically poor differentiation of the cortex and the white matter.

Our observation in sibs indicates a considerable spectrum of phenotypic and prognostic variability of this condition. In case 1 , the birth length was $-5 \cdot 2$ SD, whereas it was -9 SD in case 2 . The radiological changes were also more severely expressed in case 2 as shown by more pronounced platyspondyly, coronal clefts of vertebral bodies, thin ribs, and marked shortening of the first metacarpals. The variable prognosis is shown by the short survival of 6 months in case 2, whereas case 1 died at the age of $5 \frac{1}{2}$ years, and is the oldest documented patient with this condition. Thus, considerable intrafamilial variability has to be expected in this disorder in keeping with the well known interfamilial variability in microcephalic osteodysplastic primordial dwarfism (MOPD).

With regard to the nosology of MOPD, Majewski et $a l^{10}$ felt that mainly radiological characteristics rather than clinical ones would allow the distinction between types I and III MOPD. While common features in both types are severe intrauterine dwarfism, severe microcephaly, and similar facies, in type I dwarfism was more disproportionate with short
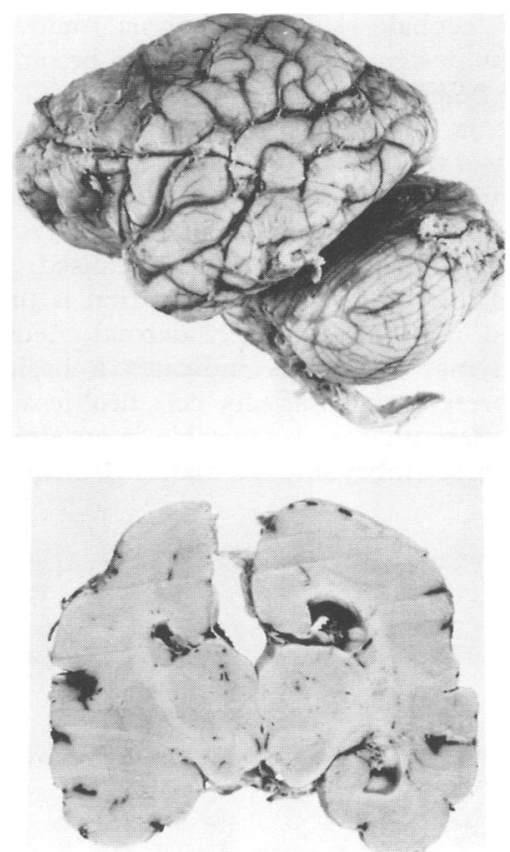

Figure 9 Case 2. Lateral view of the micrencephalic brain (above) and coronal section (below). Note hypoplastic, lissencephalic frontal lobes and absent corpus callosum. 
and bowed humeri and femora, the skull was not dolichocephalic, the pelvis was less 'dysplastic', and there were no medial spurs of the ischial bones. On the other hand, type III is thought to be characterised by a dolichocephalic skull, elongated clavicles, platyspondyly, marked 'dysplasia' of the pelvis, and enlargement of the proximal femoral metaphyses.

The present pair of sibs share characteristics of both types I and III. Our case 1 could be classified as type I MOPD, whereas case 2 would better fit type III, as postulated by Majewski et al. ${ }^{10}$ Thus our observation supports the hypothesis of Winter $e t a l^{6}$ that types I and III MOPD probably constitute one and the same entity. The same conclusion has been reached by Haan $e t a l^{7}$ and by Meinecke $e t a l^{8}$ on the basis of isolated patients. It is not yet clear whether the patients originally described by Taybi and Linder,' named 'cephalo-skeletal dysplasia', as well as the patients published later by Thomas and Nevin ${ }^{11}$ and by Lavollay $e t a l^{12}$ belong to the same disorder. However, clinically and radiologically the similarity among these patients, in particular with the observation of Majewski et al,,$^{10}$ who classified them as type III MOPD, is so convincing that we think this is one and the same entity. Agreeing that there is a 'type II' MOPD, as proposed by Majewski et $a l^{4}$ on the basis of their observations and the previously published patients of Brizard $e t a l^{2}$ and Anoussakis et al, ${ }^{3}$ it would now be reasonable to classify MOPD into type I (including the published cases of 'cephalo-skeletal dysplasia') and type II. Thus, the designation 'type III' can be omitted for the time being.

There is now sufficient evidence for a genetic aetiology of this condition. Parental consanguinity ${ }^{913}$ and occurrence among sibs of different sex $^{9}$ (this report) corresponds to autosomal recessive inheritance. The gene has not yet been localised.

The pathogenesis of this condition is unknown. Impaired maturation of ectodermal, neural, and mesenchymal structures indicates a basic defect which preferentially affects cell proliferation and tissue differentiation. Noticeable is an almost total lack of early embryonic anomalies. Further studies should involve thorough histological and electron microscopical investigations of neural tissues as well as in cultured cells. This group of disorders might result from mutations of genes that are important in the embryonic and fetal development of neural differentiation and proliferation.

We are grateful to Dr Elke Schaefer, paediatric radiologist in Hamburg, for diagnostic evaluation of the radiographs. We also thank Professor Gunschera (Bremen) for kindly providing radiographs of these patients.

1 Majewski F, Goecke T. Studies of microcephalic primordial dwarfism. I. Approach to a delineation of the Seckel syndrome. Am f Med Genet 1982;12:7-21.

2 Brizard J, Mimouni M, Seneze J, Thoyer-Rozat J. Sur un cas de nanisme extrème à début intra-utérin vraisemblablement du type Seckel. Ann Pediatr 1973;20:655-60.

3 Anoussakis C, Liakakos D, Zervos N, Karpathios T. Les nanismes congénitaux avec dysmorphie. II. Le nanisme congénital à tête d'oiseau (type Virchow-Seckel). Pédiatrie 1974;29:261-7.

4 Majewski F, Ranke M, Schinzel A. Studies of microcephalic primordial dwarfism. II. The osteodysplastic type II of primordial dwarfism. Am 7 Med Genet 1982;12:23-35.

5 Verloes A, Lambrechts L, Senterre J, Lambotte C. Microcephalic osteodysplastic dwarfism (type II-like) in siblings. Clin Genet 1987;32:88-94.

6 Winter RM, Wigglesworth J, Harding BN. Osteodysplastic dwarfism: report of a further patient with manifestations similar to those seen in patients with types I and III. $A m \mathcal{F}$ Med Genet 1985;21:569-74.

7 Haan EA, Furness ME, Knowles S, et al. Osteodysplastic primordial dwarfism: report of a further case with manifestations similar to those of types I and III. Am $\mathscr{f}$ Med Genet 1989;33:224-7.

8 Meinecke P, Schaefer E, Wiedemann HR. Microcephalic osteodysplastic primordial dwarfism: further evidence for identity of the so-called types I and III. Am $\mathcal{F}$ Med Genet 1991; 39:232-6.

9 Taybi H, Linder D. Congenital familial dwarfism with cephaloskeletal dysplasia. Radiology 1967;89:275-81.

10 Majewski F, Stoeckenius M, Kemperdick H. Studies of microcephalic primordial dwarfism. III. An intrauterine dwarf with platyspondyly and anomalies of pelvis and clavicles - osteodysplastic primordial dwarfism type III. Am $\mathcal{F}$ Med Genet 1982;12:37-42.

11 Thomas PS, Nevin NC. Congenital familial dwarfism with cephalo-skeletal dysplasia (Taybi-Linder syndrome). Ann Radiol 1976;19:187-92.

12 Lavollay B, Faure C, Filipe G, Branca G, Huet de Barochet Y. Nanisme familial congénital céphalo-squelettique (syndrome de Taybi-Linder). Arch Fr Pediatr 1984;41:57-60.

13 Majewski F, Spranger J. Case report 49. Syndrome Identification 1976; IV:17-21. 